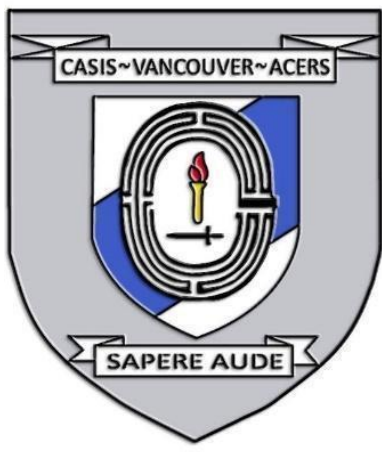

\title{
COUNTERING VIOLENT EXTREMISM: PERSPECTIVES FROM THE AUSTRALIAN CONTEXT
}

Date: November $25^{\text {th }}, 2020$

Disclaimer: This briefing note contains the encapsulation of views presented by the speaker and does not exclusively represent the views of the Canadian Association for Security and Intelligence Studies.

\section{KEY EVENTS}

On November $25^{\text {th }}, 2020$, RADAR Solutions Director and Adjunct Fellow at Victoria University Shandon Harris-Hogan spoke on the topic of Countering Violent Extremism: Perspectives from the Australian Context at the 2020 CASIS West Coast Security Conference. The presentation was followed by a question and answer period with other speakers. The key points of discussion focused on terrorism in Australia and Canada before and after ISIS spokesperson Muhammad al-Adnani delivered a speech in September 2014, and its implications for countering violent extremism (CVE).

\section{NATURE OF DISCUSSION}

\section{Presentation}

Mr. Harris-Hogan centered his presentation on comparing data from terrorist attacks from before and after Muhammad al-Adnani's speech in 2014, as well as highlighting the predominance of teenagers amongst extremist actors. He then argued that CVE program policies that focus on a secondary level intervention framework might be more effective than those focused on targeted prevention programs which have the potential to stigmatise communities.

\section{Question Period}

The question period focused on CVE and the role of the Internet and social media in the radicalization process. 


\section{BACKGROUND}

\section{Presentation}

Terrorism threats in Australia before 2014 - mostly described as small but persistent — were arguably predominantly from jihadists; data shows that 0 successful attacks were perpetrated, and 4 major attacks were foiled. However, in September 2014, ISIS spokesperson, Muhammad al-Adnani, seemed to call for refocusing the attention of Western-based supporters to attacking the foreign enemies, which appeared to have been a critical point. Since September 2014, Australia has experienced 7 successful Jihadist attacks, 16 major disruptionss and an $800 \%$ increase in terrorism related arrests. Although Canada's Jihadist experience has been broadly comparable to Australia, the changes post-2014 have been less dramatic.

In Australia, prior to 2014, the average age of those arrested was older than 28 years old. As of September 2014, after al-Adnani speech, this number dropped to 23 years old, and almost $40 \%$ of those arrested in the last five years were teenagers, compared to none in the previous decade. Incidentally, al-Adnani appears to have influenced the emergence of teenage extremist actors in Australia. By analyzing the prison population, it is possible to understand the challenge: the largest number of constraints in Australia among those who support al-Qaeda or other affiliated groups are teenagers, and each one of them were directly related to ISIS activities. So from a nonexistent threat, almost overnight, teenagers have become a significant part of the counterterrorism concern, which presents a whole different set of challenges for those working underground. As a comparison, Canada has also experienced a drop in the age of jihadist offenders since 2014 — from 27.6 to 24.9 years old — just not as sharply as in Australia.

CVE has become a popular term used by governments, academics, and NGOs to refer to non-coercive attempts to reduce involvement in terrorism, which encompasses activities previously described as counter-radicalization. The term radicalization first appeared about 20 years ago, and it remains both contested and widely misunderstood making it difficult, therefore, to devise a solution. Consequently, the ambiguity associated with radicalization has extended into the policy response designed to address that problem, namely, countering violent extremism. The lack of a clear definition or understanding resulted in policies that tended to also be broad - e.g., moving from CVE to P/CVE which added a prevention element before the countering, further expanding what was already a 
poorly defined concept and transforming it into an ever more vague amorphous field.

Prior to 2014, only one of the 87 CVE programmes established in Australia actually engaged individuals that could be considered to be on a radicalisation trajectory. For that reason, the emphasis of Mr. Harris-Hogan's work was on programmes that aimed to prevent radicalization and build community resilience amongst specific communities. Most of the prevention efforts in Australia have been underpinned by the same broad assumption that increasing community resilience or increasing social cohesion will decrease the number of radicalised individuals. However, those CVE prevention programmes were unable to demonstrate any significant links between their work at the preventative stage and specific outcomes with regards to national security and violent extremism. For the most part, the prevention efforts to find at-risk of radicalization individuals using broad definitions and geographic focus have created at least two problems: the wrong people could be targeted, and the risk of stigmatizing and labelling certain communities as national security problems.

So what are the other options to manage at risk individuals in Australia? At risk individuals in Mr. Harris-Hogan's research are individuals that might be returning from conflict sites; or those who had their passports cancelled and are prevented from travelling; or individuals leaving prison and are connected socially or through family networks to jihadists. Then, how can national security agencies, frontline services, and communities support these individuals on a daily basis? There is not a simple and definite answer to those questions. HarrisHogan's research seems to indicate that each region needs to tailor interventions to meet local conditions, and each intervention should focus on achieving behavioural disengagement, instead of preventive measures based on reducing levels of risk.

\section{Question Period}

Mr. Harris-Hogan's research showed that there are improvements to be implemented in CVE programs. However, a lot of government level delegations and events come up with high level policy statements that rarely translate into practice. There is always the danger of wanting to reinvent the wheel when there already exist services or programs to deal with a problem. It is important to realize it is cheaper to tap into the resources that already exist, and though we have not figured out what to do, we have figured out what not to do. Therefore, reshaping the framework or adjusting the focus might be financially more beneficial. 
Over the last 20 years, research has shown that jihadist networks in social media platforms are increasing; however, in almost every case, the Internet reinforces already existing beliefs of like-minded individuals. In the extremism context, there have been cases of individuals with severe mental health issues being barred from online networks. Later, data showed that those outliers had an external human influence that re-sparked and sustained the radicalization process. The Internet certainly plays a role in the radicalization process, but the idea that social media or the Internet have changed the way individuals radicalise is questionable. The majority of cases involving deadly extremist attacks seem to indicate that the radicalization process is an intensely social process, and few cases involve individuals radicalized through social media.

\section{KEY POINTS OF DISCUSSION}

\section{Presentation}

- Since September 2014, Australia has experienced 7 successful Jihadist attacks, 16 major disruptions, and an $800 \%$ increase in terrorism related arrests.

- In Australia, prior to 2014, the average age of those arrested under terrorism charges was older than 28 years old. After al-Adnani's speech in September 2014 , this number dropped to 23 years old.

- The lack of a clear definition or understanding of radicalization results in policies that tend to be broad.

- Most prevention efforts in Australia have been underpinned by the broad assumption that increasing community resilience or increasing social cohesion will decrease the number of radicalised individuals.

- Prevention efforts that use broad definitions and a geographic focus might create two problems: the wrong people could be targeted, and the risk of stigmatizing and labelling certain communities as national security problems.

\section{Question Period}

- A lot of government level delegations and events come up with high level policy statements that rarely translate into practice.

- It is important to realize it is cheaper to tap into the resources that already exist, and though we have not figured out what to do, we have figured out what not to do.

- The Internet reinforces already existing beliefs of like-minded individuals. 
- The Internet certainly plays a role in the radicalization process, but the idea that social media or the Internet have changed the way individuals radicalise is questionable.

- The majority of cases involving deadly extremist attacks seem to indicate that the radicalization process is an intensely social process, and few cases involve individuals radicalized through social media.

\section{(c) (†) $\ominus$}

EY NC ND This work is licensed under a Creative Commons Attribution-

NonCommercial-NoDerivatives 4.0 International License.

(C) (Shandon Harris-Hogan, 2021)

Published by the Journal of Intelligence, Conflict, and Warfare and Simon Fraser University

Available from: https://jicw.org/ 